\title{
The Level of Students of the Arabic-language Department in Oral Skills from the Students' Perspective
}

\author{
Dr. Ali Sami Ali Al-Halaq \\ Associate Professor in Curricula and Arabic-Language Teaching Methods \\ Faculty of Languages and Arts - Jadara University
}

\begin{abstract}
The study aims to examine the degree to which students of the Arabic Language Department at the University of Jadara possess oral-skill expression from the students' perspective. The subjects that the study has examined consists of (197) male and female students in the Arabic-Language Department at Jadara University in the first semester of the academic year 2019/2020. The researcher has comprised a questionnaire which has (46) paragraphs divided in ten fields. The study has concluded that the field of "courtesy-related skills" came first, followed by the field of "sound-related skills", then the field of "skills related to the speaker' psychological features", then the field of "skills related to eye-movement and facial expressions." After that comes the "skills of speech fluency." Then the "cognitive-related skills," and the "skills of context (style)." Then, the "vocabulary-related skills." Then the morphology-and-syntax-related skills." At last has come the sub-context-related skills." However, there has been no statistical significant differences based on the gender, the academic level, or the GPA factors. From the perspective of the Arabic Language-and-Literature Department at the Jadara University.
\end{abstract}

Keywords: Skills of oral expression, Students of the Arabic Language, Jadara.

DOI: $10.7176 / \mathrm{JEP} / 11-8-03$

Publication date:March $31^{\text {st }} 2020$

Introduction:

"My Lord, expand for me my breast. And ease for me my task. And untie the knot from my tongue that they may understand my speech." (The Holy Qur'an. Taha: 25-27)

Expression is stating and clarifying thoughts, ideas, and meanings in a fluent language and an eloquent style. It is the skill that humankind needs in all their life phases. It is also a method of comprehending and communicating with others. The purpose of language-teaching and all its linguistic fields are ways of oral and written expression. Therefore, we study the language syntax in order to attain fluency in speech and writing. Additionally, we learn dictation to master writing according to the correct dictation structure. We also study literary texts to enrich our linguistic repertoire and stylistics, which aid us with expressing. Thus, expression is the corner-stone of linguistic sciences.

\section{Discussion:}

Oral expression is considered the base of written one. Academics have collectively agreed on the fact that enhancing students' abilities of speech and good oral expression is probably the most important aspect of languagelearning. Furthermore, the most important factors of eloquence and cultural elitism are: learners' ability of expressing their needs and conversing about them, using prestigious phrases that lack inaccuracies, and is characterised by clarity, beauty, and intactness. (Al-Halaq, 2010, 69)

It has been observed that a large number of students across different phrases suffer from a conspicuous weakness in expressing either orally or written-wise. For instance, if one speaks in a fluent language, the signs of irritation are easily noticed. In fact, one might stop out of a sudden before he completes his thought, might reside in, using a colloquial form by injecting it into his speech, or to complete what has failed to convey. (Souman, 2014, 182). Previous researches and studies in the field of oral-skill-teaching have hinted at a severe weakness and drop in the level of teaching the skills that they possess. (Al-Halaq, 2013), (Al-Khamaiseh, 2012), (Al-Swerki, 2011), (Al-Saffooh, 2007), (Al-Othman 1999), (Al-Kalbani, 1997), (Nasser, 1995), and the study of (Abd Al-Hameed, 1986). Moreover, through what has the researcher noticed during his teaching that there is a severe weakness and a drop in the skills of oral-expression that the students have, the amount of fear and confusion, reflected while orally expressing themselves. Also, the researcher has observed the scarcity of the studies, discussing the level of possessing oral-expression skills across Jordanian universities' students from their own perspective.

The Study's Enquiries:

The Study aims at recognising the level of Arabic-Department Students' Possession of oral-skill expression by answering the following the following questions:

1. What is the possession level of the oral-skill expressions from the perspective of Arabic-Department Students' at Jadara University?

2. Are there any statistically significant differences in the judgement of the subject members in having oral-skill 
expression from their own perspective attributed to the following variables: gender, academic level, GPA, and the relation amongst them?

Study's Objectives:

The study is objected to the following:

1. To know the possession level of the oral-skill expressions from the perspective of Arabic-Department Students' at Jadara University.

2. To know the effect of the factors of gender, academic level, GPA, and the relationship amongst them in determining the responses of Arabic-Department Students' at Jadara University towards their possessing the oralskill expressions from their perspective.

Study's Importance:

The study's importance relies in exposing the possession level of oral-skill expressions from the perspective of the Arabic-Department Students at Jadara University. Thus the study has gained its importance out of the following:

1. The study subject's importance is reflected in investigating the basic oral-expression skills amongst the Arabic-Department Students in the fields of: thought-related skills, phrasal and vocabulary skills, stylerelated skills, sub-context-related skills, morphology-and-syntax-related skills, phonics-related skills, fluency-related skills, courtesy-related skills, skills related to the speaker's appearance and his psychological characteristics, and skills related to facial expressions, and eye-movements.

2. The study subjects are Arabic-Department students in the faculty of arts and literature at Jadara University.

3. The study also aims at providing suggestions and recommendations that could aid in enhancing the oralskill expressions across the Arabic-Department students at Jadara University.

Procedural Definitions:

Skill: the ability to perform in an easy, fast, accurate way of doing the task with the ability to adapt in accordance with the changing environment.

Oral-Expression: the ability of delivering the oral message in an organised-thought, fluent language, clear pronunciation, and the expressive performance in-lined with gestures and body-language.

Oral-Skill Expression: a collection of oral performances carried out by the students of the Arabic-Language Department at Jadara University during the oral-communication situations, including the aspects of: ideas, vocabulary, style, context, morphology and syntax, fluency, and body-language provided that the performances have speed, accuracy, and mastery in order to convey their ideas, feelings, experience, and opinions in a way that leads to the listener's interaction and response. This is measured by the total grade the student gets corresponding to the study tool.

Students: the Arabic-Department students who are in their second, third, and fourth year in the first academic term 2019/2020 at Jadara University.

The Study's Settings:

1. Time Settings: the first term of the academic year 2019/2020

2. Spatial Settings: Arabic-Department Students at Jadara University.

3. Subjective Settings: the study has only covered the oral-expression skills, set by the researcher in the questionnaire and approved by the jury.

Expression Types:

Expression types are divided into performance and style (Al-Bajjeh, 2010, 217):

1. Oral Expression: It is for the human being to orally convey his thoughts and feelings to others, using the language that helps him or her, such as: emotes, hand-gestures, facial expressions, and intonation.

2. Written Expression: It is the human being's ability to provide a clear, well-displayed, accurate writings to express his sentiments in a cohesive and connected style and thought.

Oral Expression:

One learns oral expression before the written expression through communication with others surrounding him at home since home is the initial school to gain oral expression. Therefore, if his cultural and social status are prestigious, his ability to learn is expedited. However, if they are low, this will lead to an overall weakness in the learning process. (Al-Sayyed, 2017, 18)

Oral-Expression Concept:

According to Safasefah $(2010,178)$, "it is when the student discloses his thoughts, sentiments, experiences using 
a fluent Arabic language."

However, when it comes to Al-Rabai'ah and Al-Habashneh $(2015,631)$, they say, "it is the expression of thoughts, using correct morphology and syntax, adding the suitable body-language according to the situation. The researcher suggests that the oral-expression is one's ability to convey his ideas, feelings, beliefs, to the listener, utiliising an organised style, fluent language, correct speech, with body and facial expressions.

Oral-Expression-Teaching Objectives:

Oral-expression seeks to achieve the following (Ata, 2006, 152):

1. Habitualising students to correct pronunciation, fluency, and vocabulary-employment.

2. Habitualising students to logical-thinking, idea-organising-and-linking.

3. Enriching self-confidence via confronting his peers in or out the school.

4. Empowering the students to express their surroundings, and experiences, in or outside the school in a correct manner.

5. Overcoming some psychological obstacles that might affect the child, such as: shyness, stammering while talking, or introversion.

6. Enhancing speech skills, such as: debating and showcasing opinions and ideas by speech-delivering.

7. Discovering the talented students in the fields of speech-delivering, improvising, fluency, and idea accuracy.

8. Improving the other side of expression: written expression, resulting in cultivating the student's linguistic repertoire.

Oral-Expression Skill:

Specialists have gone over oral-skill expression in their researches and studies. (Ahmed, 2015, 137) and (Madkour, 2007, 185) suggest that the fundamental skills for oral expression in student-teaching are:

1. Pronouncing phonics in a clear way to the listeners.

2. The ability to obtain a suitable amount of vocabulary, and utilising it.

3. Employing the appropriate words that denote clear ideas.

4. The ability to exemplify and cite what one says.

5. The total control over all what he says.

6. The ability to realise the importance of having something to discuss with others.

7. The ability of using the right intonation.

8. The ability to choose and organise the idea of his topic's context.

Previous Studies:

Al-Halaq study (2013), whose aim is to diagnose the teaching difficulties in oral-skill course from the studentand-teacher perspective amongst the elementary students in Al-Miqdadiyeh County Centre. The researcher has followed the descriptive method. The study has consisted of 24 Arabic teachers (both genders) in the governorate of Diyyali, and 1934 students (both genders) from the ones that attend elementary day-school. To achieve the purpose of the study, the researcher has developed two questionnaires: the first of which includes 89 paragraphs for the teachers, whereas the second has consisted of 92 paragraphs for the students. The study has concluded that the students' weakness is referred to the following: Arabic-language teachers have not viewed the purpose of teaching oral-expression, the time dedicated to oral-expression classes is not adequate to achieve these purposes, the lack of utilising the school's library in choosing the subjects, teachers goad the students to discuss one subject, the limitedness of subjects assigned to the elementary students, and most subjects do not take into consideration the intellectual level of the students.

Al-Khamiseh's study (2012) which has aimed at knowing the range of oral-skill expression skills in the Education Faculty at Ha'el University from the students' perspective, and the struggles they face in the lecturehall. The study subject has consisted of all the students of the education faculty at Ha'el University, as follows: 305 male and female students, in order to achieve the study goals, the researcher has used a tool of 46 paragraphs, divided into five aspects, such as: cognitive, linguistic, phonic, the gestural, and the struggles that the educationfaculty students face at Ha'el university. The study has shown that the gestural aspect has come in first, followed by the phonic, cognitive, and at last the linguistic, whereas the major struggle is related to the extensive use of traditional lecturing, in addition to the overwhelming shyness that suppress students from talking in front of their peers. The total average of the study has come as follows: oral-expression has scored 2.9, equivalent to $58 \%$, besides the gender-related factors leading to major distinctions in the favour of females.

Al-Swerki's study (2011) which aims to assess the performance in oral expression amongst elementary students in Jordan, to determine the necessary oral-expression skills for seventh graders, and to recognise the level of the study subject, which has consisted of elementary students in Jordan as follows: 54 male and female of seventh graders in the directorate of education in Irbid. Furthermore, the researcher has used the questionnaire tool, 
consisting of 20 statements divided into five major aspects: vocabulary, sub-context, phonics, morphology and the speaker's psychological features in order to achieve the study goals. Generally, the level of oral-expression was not satisfying, where the total performance is $54.3 \%$, meaning that the overall performance was low as the study has indicated.

Jawad's study (2009) which aims to pinpoint the reasons behind the oral-expression weakness in the elementary level from the teachers' perspective. In this study, the researcher has used the descriptive method, where the study subject has included 143 Arabic teachers from both genders, who work in day schools of Al-Karkh directory in Baghdad during the academic year of 2004/2005. To achieve the study goals the researcher has used a note card consisting of 27 paragraphs distributed into four fields as a triple-scale. The study has concluded that the main reason behind the weakness is that some students come from culturally shallow families, which has caused their linguistic weakness. In other words, some families do not concern themselves in incorporating their offspring in their social interactions, such as: conversing with them or others, not giving them the chance to listen, in addition to the scarcity of improvising, or out of disinterest in the selected subjects, discouraging students from extracurricular readings.

Al-Sfouh's study (2007) aiming at evaluating situational oral-expression skills of ninth graders in the light their linguistic repertoire and genders. The study subject has consisted of 102 students from both genders randomly selected. The researcher has used a note card to analyse the oral linguistic performance, resulting in statistically distinguished differences amongst the performance average of ninth graders. For instance, in terms of the oralskill expression, it is in the favour of females, whereas the linguistic accumulation are in the favour of those with a high level.

Al-Kalbani's Study (1997) aimed at showcasing oral-expression skills required by the female students in the elementary stage, and to distinguish the level of these skills upon them, and in order to achieve the earliermentioned goal, the researcher has prepared two lists, the first of which has included the following skills: pictureand-painting reading, story-telling, orally completing stories, conversation, oratory, discussion, courtesy, phonetalking, instructing, relation-building, apologising, and description. Whereas the second list has included the subskills for each field. The study has suggested that the female students suffer from a general weakness in oralexpression skills, where they lack the ability to express themselves fluently.

Abd-Alhameed's Study (1986) whose purpose is to discover the oral-expression skills and its fields that are suitable for the elementary-stage students. Additionally, it also points out the level to which students are able to master such skills, and constructs enrichment programmes, whose study subject has included 600 randomly selected students from both genders. Therefore, to achieve that, the researcher has comprised two questionnaires: the first of which includes oral-expression skills suitable for elementary-stage students. While the second of which has tackled the preferred oral-expression fields. The study has hinted at a plethora of results, namely: students' oral-expression weakness is attributed to a wide range of causes, such as: the inaccuracy of the study plan, the overall weakness in Arabic teachers, the lack of a curriculum that teaches students how to express each class on its own, and not bearing in mind the students' interests when it comes to select the oral-expression topics handed to them.

Comments on Related Studies:

The researcher has used the previous studies to prepare the study tool, comparing results and explaining them. This study is distinguished by:

A - It tackles the Arabic-department student's position level of oral-expression skills in the fields of: ideas, vocabulary, style, sub-context, morphology and syntax, phonics, fluency, courtesy, the speakers' appearance and psychology, eye-movement and facial expressions.

B - It is the first study - as far as the researcher knows - to tackle Arabic-department students' level of the oralexpression skills at Jadara University within its ten aspects.

Method and Procedures:

Study Methodology:

The researcher has followed the descriptive approach as it is the best approach for such a study, for it describes the phenomenon as is and explains it.

Study community: the study community consists of the Arabic-department students at Jadara University during the first academic term 2019/2020 as a total number of (480) students from both genders.

Study subject: after determining the study community, the researcher has randomly selected the study subject as he distributed 200 questionnaires and received back 197 questionnaires.

Table 1 shows the distribution of the study subject according to the variables: 
Table (1)

Distribution of the study subject according to the personal variables

\begin{tabular}{|r|r|r|r|}
\hline Variable & Level & Repetition & Percentage \\
\hline \multirow{3}{*}{ Gender } & Male & 76 & 38.6 \\
\cline { 2 - 4 } & Female & 121 & 61.4 \\
\cline { 2 - 4 } & Sum & 197 & 100.0 \\
\hline \multirow{3}{*}{ Academic } & Second & 55 & 27.9 \\
\cline { 2 - 4 } Year & Third & 90 & 45.7 \\
\cline { 2 - 4 } & Forth & 52 & 26.4 \\
\cline { 2 - 4 } & Sum & 197 & 100.0 \\
\hline \multirow{3}{*}{ GPA } & Weak & 4 & 2.0 \\
\cline { 2 - 4 } & Fair & 19 & 9.6 \\
\cline { 2 - 4 } & Good & 71 & 36.0 \\
\cline { 2 - 4 } & Very good & 85 & 43.1 \\
\cline { 2 - 4 } & Excellent & 18 & 9.1 \\
\cline { 2 - 4 } & Sum & 197 & 100.0 \\
\hline
\end{tabular}

Study Tool:

To answer the study questions and achieve its goals, the researcher has developed a tool to measure oral-expression skills amongst the study subject. After the researcher has reviewed the research parameters in this field and benefiting from the earlier studies' scales: (Al-Khamayseh 2012) (Al-Swerki 2011). The study tool consists of two parts:

1- First part: consists of personal information related to: gender, academic level and GPA.

2- The second part: consists of 46 parts showing the level of oral-expression skills, divided into 10 aspects: idearelated skills, vocabulary-related skills, style-related skills, context-related skills, morphology-related skills, phonic-related skills, fluency-related skills, courtesy-related skills, physiology-related skills and eye-movementand-facial-expressions skill. A scale of five degrees has been used to answer each part. Each part has been given the following answer: (Very high, High, Average, Weak, Very weak) degrees as follows $(1,2,3,4,5)$. The participant level is calculated by summing his degrees in each aspect and summing the degrees of all aspects to get the total sum of the questionnaire. The participant's degree averages between (46-230). Therefore, in order to comment on the arithmetic average, the researcher has set three levels as the following:

Low level: (1 - less than 2.33)

Average level: (2.33 - less than 3.67)

High level: (3.67 - less than 5.00)

Study-Tool Veracity:

The study tool has been reviewed by a number of judges experienced in teaching methods and Arabic-Language and literature from Jadara and Al Yarmouk Universities, to assure the efficiency of the study tool paragraphs. The researcher has benefited from the judges' comments by adjusting the language and the paragraphs' structure, in addition to deleting and readjusting some of the paragraphs. The researcher has also used the paragraphs accepted by the judges, resulting in the final shape of the tool, divided into 46 paragraphs tackling the oral-expression areas.

Study-Tool Consistency:

The researcher has assured his tool consistency by applying Alpha Cronbach test, the internal consistency factor scored (0.93) which is suitable for the study purposes according to researcher's perspective. Table (2) shows the consistency rate for each aspect of the study and for the tool in total. 
Table (2)

Alpha-Cronbach factors for each aspect of the study tool and for the tool in total.

\begin{tabular}{|r|r|}
\hline Aspect & $\begin{array}{r}\text { Alpha-Cronbach } \\
\text { Factor }\end{array}$ \\
& 0.82 \\
\hline Idea-related skills & 0.75 \\
\hline Vocabulary-related skills & 0.73 \\
\hline Idea-related skills & 0.79 \\
\hline Vocabulary-related skills & 0.81 \\
\hline Style-related skills & 0.83 \\
\hline Sub-context-related skills & 0.77 \\
\hline Morphology-and-syntax-related skills & 0.80 \\
\hline Phonic-related skills & 0.82 \\
\hline Fluency-related skills & 0.78 \\
\hline Courtesy-related skills & 0.91 \\
\hline Phonological-and-appearance-related skills &
\end{tabular}

As table (2) shows all of Alpha Cronbach factors are high, which indicates the veracity of the study tool.

Tool-Checking Methods:

Study Variables:

Independent Variables:

Gender: (male, female)

Academic Level: $\left(2^{\text {nd }}\right.$ Year, $3^{\text {rd }}$ Year, $4^{\text {th }}$ Year $)$

GPA: (Excellent, Very good, Good, Average, Weak)

Dependent Variable: Oral-expression skills for Arabic department students at Jadara University from the students' perspective.

Study-Applying Procedures:

1- Conducting the study and ensuring its consistency.

2- Distributing the study tool to the study subject and teachers in Irbid's governorate asking them to answer the tool according to their perspective as the following: Very high with 5 degrees, High with 4 degrees, average with 3 degrees, low with 2 degrees or extremely low with 1 degree.

3- The questionnaires have been collected, examined, and processed their data through the computer to conduct the required analytic processes on the subject's questions, using SPPS program.

Statistical Processing:

The following statistical processing have been applied:

1- Alpha Cronbach: to ensure the study-tool consistency and how constantly applicable it may remain.

2- Standard deviation and arithmetic has been applied to diagnose the level of oral-expression skills for Arabicdepartment students at Jadara University from their perspective, according to (gender, academic year, GPA) factors. 3- Applying (Independent Samples T-Test) on the study tool in its entirety according to the gender factor on the level of oral-expression skills for the Arabic-department students at Jadara University.

4. Analysis of Variance (ANOVA): to know if there is any difference in determining the level of the holistic quality standards that should be attributed to the academic year, qualification and how they interact.

Study Results:

After analysing data, and in light of possessing the study questions and variables the results are as follows:

Question-One Results tackle the levels of oral-expression skills in the Arabic department students at Jadara University from their perspective on the following aspects: ideas-related skills, vocabulary-related skills, stylerelated skills, sub-context related skills, morphology and syntax- related skills, phonic related skills, fluencyrelated skills, courtesy-related skills, physiological can appearance-related skills, eye movement and facial expressions-related skills.

To answer this question the researcher has extracted the standard deviation and arithmetic of the study subject answers on the study tool, as table 3 shows: 
Table (3)

Standard deviation and arithmetic of the study subject answers on the study-tool fields in descending order of the arithmetic:

\begin{tabular}{|r|r|r|r|r|r|}
\hline Level & Number & Aspect & Arithmetic & $\begin{array}{r}\text { Standard } \\
\text { Deviation }\end{array}$ & Grade \\
\hline 1 & 8 & Courtesy-related skills & 4.08 & 0.82 & High \\
\hline 2 & 6 & Phonic related skills & 3.98 & 0.95 & High \\
\hline 3 & 9 & Physiological and appearance-related skills & 3.89 & 0.82 & High \\
\hline 4 & 10 & Eye-movement and facial expressions-related & & & High \\
& & skills & 3.87 & 0.98 & High \\
\hline 5 & 7 & Fluency-related skills & 3.77 & 0.85 & High \\
\hline 6 & 1 & Idea-related skills & 3.74 & 0.62 & High \\
\hline 7 & 3 & Style-related skills & 3.71 & 0.73 & High \\
\hline 8 & 2 & Vocabulary-related skills & 3.67 & 0.80 & Average \\
\hline 9 & 5 & Morphology-and-syntax- related skills & 3.64 & 0.94 & Average \\
\hline 10 & 4 & Sub-context-related skills & 3.63 & 0.70 & Average \\
\hline & & Study-Tool Total & 3.77 & 0.61 & High \\
\hline
\end{tabular}

This order indicates that courtesy-related skills have come in first according to the students' perspective, whereas the sub-context-related skills have come in last, which needs the most priority. Also, it is the sub-context that is the most essential factor in both written and oral forms. This conclusion matches with both results from AlKhamaiseh's study in 2012, and Al-Swerki's in 2011. As for the speaker's psychological, phonic, and appearance factors have come in first. Whereas the sub-context has come in last. To have a better understanding of the result regarding the study-subject skills, the researcher has extracted the arithmetic and the standard deviation of the students' answers about each aspect in the study paragraphs individually. Table (13-4) elucidates that.

Table (4)

The arithmetic and standard deviations for the study-subject students' answers regarding the cognitive-related skills in a descending order according to the average

\begin{tabular}{|r|r|r|r|r|r|}
\hline Grade & Number & Paragraph & Arithmetic & $\begin{array}{r}\text { Standard } \\
\text { Deviation }\end{array}$ & Rate \\
\hline 1 & 6 & Highlighting the Topic's Main Idea & 4.13 & 0.82 & High \\
\hline 2 & 9 & Adhering to the Topic's Main Subject & 3.88 & 0.92 & High \\
\hline 3 & 5 & Linking Main and Sub-ideas & 3.82 & 0.88 & High \\
\hline 4 & 1 & Choosing Suitable Ideas for the Topic & 3.80 & 0.86 & High \\
\hline 5 & 2 & Maintaining Ideas' Relatedness to the Main Topic & 3.79 & 0.87 & High \\
\hline 6 & 3 & Maintaining Ideas' Coherence & 3.69 & 0.91 & High \\
\hline 7 & 7 & Supporting the Main Idea & 3.61 & 1.01 & Average \\
\hline 8 & 8 & Fully Showcasing ideas & 3.58 & 0.91 & Average \\
\hline 9 & 4 & Avoiding Digressions to Maintain Idea-Centrality & 3.33 & 1.01 & Average \\
\hline & & Cognitive-Related Skills as a Total & 3.74 & 0.62 & High \\
\hline
\end{tabular}

As table (4) shows the average of the study-subject answers on the idea-related skills has ranged between (3.33-4.13). Paragraph 6 discusses highlighting the topics' main idea has come first with average of (4.13) with a high degree Whereas paragraph (4) goes over avoiding digressions in favour of idea-centrality has come last with an average of (3.33) having an average rating. The total average of idea-related skills is (3.74) with a high rating, indicating that the students' weakness in generating ideas. The researcher clarifies that the issue is caused by the fact that a large number of students are intellectually and culturally poor. Also, the researcher hints at many students do not enjoy uninterrupted, sustained reading. This finding agrees with the results of (Al-Khamayseh 2012) and (Al-Swerki 2011) studies.

Table (5)

The arithmetic and standard deviations for the study-subject students' answers regarding the Vocabulary-related skills in a descending order according to the average

\begin{tabular}{|r|r|r|r|r|r|}
\hline Grade & Number & Paragraph & Average & $\begin{array}{r}\text { Standard } \\
\text { Deviation }\end{array}$ & Rate \\
\hline 1 & 1 & Choosing Suitable Vocabulary Matching the & 4.12 & 0.93 & High \\
\hline 2 & 4 & Topic & & 1.03 & Average \\
\hline 3 & 2 & Vocabulary Correctness and Accuracy & 3.55 & 0.99 & Average \\
\hline 4 & 3 & Employing Varying Vocabulary & 3.54 & 1.07 & Average \\
\hline \multicolumn{7}{r|}{} & Vocabulary-related skills in General & 3.67 & 0.80 & High \\
\hline
\end{tabular}


As table (5) shows the average of the study-subject answers on the vocabulary-related skills has ranged between (34.7-4.12). Paragraph 1 studies choosing vocabulary appropriate for the topic has come first with an average of (4.12) with a high rating. Whereas paragraph (3) whose concern revolves around choosing standardArabic phrases has come last with an average of (3.47) and an average rating. The total average of vocabularyrelated skills is (3.67) with a high rating. The researcher explains that the absence of encouraging students to use standard Arabic and that some teachers do not use standard Arabic during their teaching which agrees with the results of (Al-Jbori 2012), (Al-Swerki 2011), (Al-Kalbani 1997) studies.

Table (6)

The arithmetic and standard deviations for the study-subject students' answers regarding the context-related skills in a descending order according to the average

\begin{tabular}{|r|r|r|r|r|r|}
\hline Grade & Number & Paragraph & Average & $\begin{array}{r}\text { Standard } \\
\text { Deviation }\end{array}$ & Rate \\
\hline 1 & 1 & Choosing Suitable Expressions Matching the & 3.82 & 0.94 & High \\
& & Situation & & 0.82 & High \\
\hline 2 & 2 & Matching Lexemes and Sentences & 3.77 & 0.99 & High \\
\hline 3 & 3 & Using Pronouns and Demonstratives & 3.74 & 1.13 & High \\
\hline 4 & 6 & Avoiding Distracting Sentences & 3.72 & 1.05 & High \\
\hline 5 & 4 & Using Suitable Linking Words & 3.67 & 1.08 & Average \\
\hline 6 & 5 & Mixing between Simple and Compound & 3.53 & 0.73 & High \\
\hline
\end{tabular}

As table (6) shows the average of the study-subject answers on the context-related skills has averaged between (3.53-3.82), where paragraph (1) that goes over choosing vocabulary suitable for different situations has come first with an average of (3.82) with a high rating. However, paragraph (5) which deals with mixing between simple and compound sentences has come last with an average of (3.53) and an average rating. The total average of contextrelated skills is (3.71) with a high rating. The researcher explains that the large number of courses discussing different linguistic subjects. This finding disagrees with the results of both (Jawad 2009), (Al-Kalbani 1997) studies.

Table (7)

The arithmetic and standard deviations for the study-subject students' answers regarding the sub-context-related skills in a descending order according to the average

\begin{tabular}{|r|r|r|r|r|r|}
\hline Grade & Number & Paragraph & Arithmetic & $\begin{array}{r}\text { Standard } \\
\text { Deviation }\end{array}$ & Rate \\
\hline 1 & 2 & Topic's Clarity & 3.92 & 0.92 & High \\
\hline 2 & 3 & Supporting the Main Topic & 3.75 & 0.91 & High \\
\hline 3 & 4 & Quoting Renowned Texts (Holy Qur'an and & 3.73 & 1.05 & High \\
\hline 4 & 6 & Cause-Effect Linking & 3.69 & 0.90 & High \\
\hline 5 & 1 & Precision and Conciseness & 3.59 & 0.98 & Average \\
\hline 6 & 7 & Avoiding Tautologies & 3.59 & 1.00 & Average \\
\hline 7 & 5 & Using Recommendations or Conclusions & 3.45 & 1.03 & Average \\
\hline 8 & 8 & Non-Affecting Conciseness & 3.33 & 1.02 & Average \\
\hline & & Sub-Context-Related Skills & 3.36 & 0.70 & Average \\
\hline
\end{tabular}

As table (7) shows the average of the study-subject answers on the sub-context-related skills has averaged between (3.33-3.92). As paragraph (2) examines the Subject Clarity has come first with an average of (3.92) with a high rating. In addition, paragraph (8) studies conciseness has come last with an average of (3.33) and an average rating. The total average of sub-context-related skills is (3.63) with a high rating. The researcher refers this issue to the limitedness of culture and intellect of the students, not encouraging students to extracurricular readings, not habitualising them to focus on concise and precise expression. This conclusion attests to what has been already discussed in both Al-Halaq's (2013), Al-Khamayseh's (2012), and Al-Swerki's (2011) studies. 
Table (8)

The arithmetic and standard deviations for the study-subject students' answers regarding the Morphology-andSyntax-related skills in a descending order according to the average

\begin{tabular}{|r|r|r|r|r|r|}
\hline Grade & Number & Paragraph & Arithmetic & Standard Deviation & Rate \\
\hline 1 & 1 & Correctly Pronouncing Words & 3.84 & 1.10 & High \\
\hline 2 & 2 & Not Using Diacritics on the Last Letter & 3.64 & 1.09 & Average \\
\hline 3 & 3 & Having Syntactic-Mistake-Free Speech & 3.44 & 1.11 & Average \\
\hline \multicolumn{7}{|r|}{ Morphology-and-Syntax-related skills } & 3.64 & 0.94 & Average \\
\hline
\end{tabular}

As table (8) shows the average of the study-subject answers on the Morphology-and-Syntax-related skills has averaged between (3.44-3.84). As paragraph (1) focuses on correctly pronouncing words has come first with an average of (3.84) with a high rating. Furthermore, paragraph (3) studies avoiding syntactic mistakes has come last with an average of (3.44) and an average rating. The total average of morphology and syntax-related skills is (3.63) with a high degree. The researcher comments that the students are weak in the fields of morphology and syntax across all academic levels. This finding agrees with results of, (Al-Khamayseh 2012), (Al-Swerki 2011), (Jawad 2011) and (Al-Kalbani 1997) studies.

Table (9)

The arithmetic and standard deviations for the study-subject students' answers regarding the Phonic-related skills in a descending order according to the average

\begin{tabular}{|r|r|r|r|r|r|}
\hline Grade & Number & Paragraph & Arithmetic & $\begin{array}{r}\text { Standard } \\
\text { Deviation }\end{array}$ & Rate \\
\hline 1 & 1 & $\begin{array}{r}\text { Voice-clarity by appropriately enunciating each } \\
\text { letter }\end{array}$ & 3.99 & 1.05 & High \\
\hline 2 & 2 & Pronouncing words without stammering & 3.97 & 0.97 & High \\
\hline
\end{tabular}

As table (9) shows the average of the study-subject answers on the phonic-related skills has averaged between (3.97-3.99) where paragraph (1) that focuses on voice clarity by appropriately enunciating each letter has come first with an average of (3.99) with a high rating. Furthermore, paragraph (2) exploring pronouncing words without stammering has come last with an average of (3.97) and a high rating. The total average of phonic-related skills is (3.98) with a high degree. The researcher sees that the students tend to focus on intonation and voice to make up for the lack of familiarity rather than focusing on an attractive sub-context. This conclusion agrees with results of (Al-Khamayseh 2012), and (Al-Swerki 2011) studies.

Table (10)

The arithmetic and standard deviations for the study-subject students' answers regarding the Fluency-related skills in a descending order according to the average

\begin{tabular}{|r|r|r|r|r|r|}
\hline Grade & Number & Paragraph & Arithmetic & $\begin{array}{r}\text { Standard } \\
\text { Deviation }\end{array}$ & Rate \\
\hline 1 & 1 & $\begin{array}{r}\text { Avoiding misplacing letters as a result of talking } \\
\text { quickly }\end{array}$ & 3.83 & 1.03 & High \\
\hline 2 & 2 & $\begin{array}{r}\text { Using the suitable rhythm while talking in terms } \\
\text { of slowness or fastness }\end{array}$ & 3.74 & 0.94 & High \\
\hline 3 & 3 & Using the intonation to suit the meaning & 3.74 & 0.99 & High \\
\hline
\end{tabular}

As table (10) shows the average of the study-subject answers on the fluency-related skills has ranged between (3.74-3.83) where paragraph (1) focuses on avoiding misplacing letters as a result of talking quickly has come first with an average of (3.83) with a high rating. Moreover, paragraph (2) which focuses on using the suitable rhythm while talking in terms of slowness or fastness. Whereas Paragraph (3) which deals with the ability of using the intonation to suit the meaning has come last with an average of (.3.74) and a high rating, the total average of fluency-related skills is (3.77) with a high rating. The researcher refers this finding to the fact that some students have gained the ability to control speaking rhythm. This has been caused by the extensive use of social media and the widespread availability of audio and visual materials using the appropriate intonation. The finding agrees with results of (Al-Khamayseh 2012), and (Al-Swerki 2011) studies. 
Table (11)

The arithmetic and standard deviations for the study-subject students' answers regarding the Fluency-related skills in a descending order according to the average

\begin{tabular}{|r|r|r|r|r|r|}
\hline Grade & Number & Paragraph & Arithmetic & Standard Deviation & Rate \\
\hline 1 & 2 & Appreciating others' ideas & 1.01 & 4.23 & High \\
\hline 2 & 3 & Subjectivity and Integrity & 0.97 & 4.16 & High \\
\hline 3 & 1 & Using the Suitable Courteous Phrases & 1.01 & 3.99 & High \\
\hline 4 & 4 & Being aware of Sociolinguistics & 0.98 & 3.92 & High \\
\hline \multicolumn{1}{|r|}{ Courtesy-Related Skills } & 0.82 & 4.08 & High \\
\hline
\end{tabular}

As table (11) shows the average of the study-subject answers on the courtesy-related skills has ranged between (3.92-4.23). As paragraph (2) examining appreciating others' ideas has come first with an average of (4.23) with a high rating. Moreover paragraph (4) that focuses on being aware of sociolinguistics has come last with an average of (3.92) and a high rating. It has been concluded that the total average of courtesy-related skills is (4.08) with a high rating. The researcher elaborates that courtesy-related skills represented by appreciating others' ideas and being courteous are probably one of the most significant aspects of communication, around which revolves the educational process in universities. In turn, this finding goes in-line with results of (Al-Khamayseh 2012), and (AlSwerki 2011) studies.

Table (12)

The arithmetic and standard deviations for the study-subject students' answers regarding the psychological-andappearance-related skills in a descending order according to the average

\begin{tabular}{|c|c|c|c|c|c|}
\hline Grade & Number & Paragraph & Arithmetic & $\begin{array}{r}\text { Standard } \\
\text { Deviation }\end{array}$ & Rate \\
\hline 1 & 1 & Quick wits & 0.96 & 4.03 & High \\
\hline 3 & 2 & Being Tentative & 0.99 & 3.90 & High \\
\hline 5 & 3 & Using the Appropriate Sociolinguistics & 1.05 & 3.88 & High \\
\hline 2 & 4 & Accepting Guidance and Mentorship & 1.09 & 3.86 & High \\
\hline 4 & 5 & $\begin{array}{r}\text { Having self-confidence and being literarily } \\
\text { courageous while expressing }\end{array}$ & 1.04 & 3.80 & High \\
\hline & & psychological-and-appearance-related skills & 0.82 & 3.89 & High \\
\hline
\end{tabular}

As table (12) shows the average of the study-subject answers on the psychological-and-appearance-related skills has averaged between (3.80-4.03) as paragraph (1) which tackles quick wits has come first with an average of (4.03) with a high rating. Moreover, paragraph (4), which discusses having self-confidence and being literarily courageous while expressing, has come last with an average of (3.98) and a high rating. The total average of the psychological-and-appearance-related skills is (3.98) with a high rating. The researcher explains that courtesyrelated, and quick-wit-related, and literary-related skills, especially those that dictate paying attention to the speakers' characteristics are probably the most significant aspects of oral expression. This conclusion does agree with the results of both (Al-Khamayseh 2012), and (Al-Swerki 2011) studies.

Table (13)

The arithmetic and standard deviations for the study-subject students' answers regarding the Eye-movement and Facial Expression skills in a descending order according to the average

\begin{tabular}{|l|l|l|l|l|l|}
\hline Grade & Number & Paragraph & Arithmetic & Standard Deviation & Rate \\
\hline 1 & 1 & Using appropriate signals that denote meaning & 3.94 & 1.01 & High \\
\hline 2 & 2 & Using body language that denotes meaning. & 3.79 & 1.10 & High \\
\hline \multicolumn{2}{|l}{ Eye-movement and Facial-Expression skills } & 3.87 & 0.98 & High \\
\hline
\end{tabular}

Table (13) displays the average of the answers regarding the paragraphs that tackle the skills related to the Eye-movement and Facial-Expression skills. It ranges between $(3.79-3.94)$, where paragraph (1) whose subject is, using the appropriate signals that denote meaning, has come in first with an average (3.94), with a high rating. Whereas paragraph (2) whose subject is using body language that denotes meaning has come in last with an average (3.97) with a high rating. The average for the skills related to the eye-movement and facial expressions as an entirety is (3.87) with a high rating. The researcher attributes this result to the fact that some students tend to support their speech by being meticulous with the appearance, facial expressions, and body-language because they may not have the best of memories, or they may not find the suitable ideas that go with the situation. This result does coincide with both Al-Khamyseh's study (2012) and Al-Swerki's (2011).

Question-Two Results:

Are there statistically significant differences with the statistic level $(\alpha \leq 0.05)$ reflected on the oral-expression skills of the Arabic-Department students at Jadara University according to (gender, academic level, GPA) variables? To answer this question the Arithmetic and standard deviations of the study have been extracted according to 
(gender, academic level, GPA) variables, and the (independent Samples T-Test) has been applied on the study in general according to the (gender) factor. Also, (ANOVA) analysis has been applied on the study in general according to the (GPA) and the (academic level) factors. The results are as the following

Table (14)

Independent Samples T-Test results regarding the level of Oral-Expression Skill of the Arabic-Department Students at Jadara University from their Perspective according to the gender variable

\begin{tabular}{|r|r|r|r|r|}
\hline Gender & Arithmetic & Standard Deviation & $\mathrm{T}$ & Statistical Significance \\
\hline Male & 3.73 & 0.58 & -1.17 & 0.24 \\
\hline Female & 3.83 & 0.66 & & \\
\hline
\end{tabular}

As table (14) shows there are no statically significant differences at the level of $(\alpha \leq 0.05)$ in the study-subject perspective regarding the study. (T-Test) results have not been statically significant, due to the close community of Jadara University shared by the students as they undergo the same circumstances. Nonetheless, this disagrees with the results of (Al-Khamayseh 2012) and (Al-Sfouh 2007) which indicate a statically significant difference in favor of the females.

Table (15)

The averages and Standard Deviations for the subject-study answers regarding level of Oral-Expression Skill of the Arabic-Department Students at Jadara University from their Perspective according to the Academic-Level variable

\begin{tabular}{|r|r|r|}
\hline Academic Level & Arithmetic & Standard Deviation \\
\hline Second & 3.83 & 0.45 \\
\hline Third & 3.78 & 0.64 \\
\hline Fourth & 3.69 & 0.70 \\
\hline
\end{tabular}

As table (15) shows there are statically significant differences between averages of the study subjects' answers to the study due to the academic level, and to know the statistic impact of the differences, (ANOVA) test has been applied on the study according to the academic level as table (16) shows:

$$
\text { Table (16) }
$$

ANOVA-Test Results regarding the level of Oral-Expression Skill of the Arabic-Department Students at Jadara University from their Perspective according to the Academic-Level Variable

\begin{tabular}{|r|r|r|r|r|r|r|}
\hline Field & Squares Sum & DF & $\begin{array}{r}\text { Squares } \\
\text { Average }\end{array}$ & $\begin{array}{r}\text { Statistical } \\
\text { Significance }\end{array}$ \\
\hline $\begin{array}{r}\text { The tool as } \\
\text { a total }\end{array}$ & $\begin{array}{r}\text { Amongst } \\
\text { Groups }\end{array}$ & 0.72 & 3 & 0.24 & \\
\cline { 2 - 5 } & In Groups & 73.19 & 193 & 0.38 & 0.63 \\
\cline { 2 - 5 } & Summation & 73.92 & 196 & & 0.59 \\
\hline
\end{tabular}

As table (16) shows there are no statically significant differences at the level of $(\alpha \leq 0.05)$ of the study-subject perspective regarding the study in general due to the academic level, as (F) value is $(0.63)$ which is not statically significant results. This can be attributed to the close community of Jadara university which all of the students share and also because the students study the same materials with the same lecturer. This result disagrees with the result of (Al-Sfouh) study which has shown statically significant differences in the favor of students with high GPA.

Table (17)

The averages and Standard Deviations for the subject-study answers regarding the level of Oral-Expression Skill of the Arabic-Department Students at Jadara University from their Perspective according to the GPA variable

\begin{tabular}{|r|r|r|}
\hline GPA & Arithmetic & Standard Deviation \\
\hline Weak & 3.33 & 1.56 \\
\hline Fair & 3.59 & 0.49 \\
\hline Good & 3.74 & 0.64 \\
\hline Very Good & 3.86 & 0.57 \\
\hline Excellent & 3.75 & 0.53 \\
\hline
\end{tabular}

Table (17) displays some apparent differences in the averages of the study-subject answers regarding the level of Oral-Expression Skill of the Arabic-Department Students at Jadara University from their Perspective, where ANOVA test has been applied on the study tool according to the GPA variable. 
Table (18)

ANOVA Test Results regarding the level of Oral-Expression Skill of the Arabic-Department Students at Jadara University from their Perspective according to the GPA variable

\begin{tabular}{|c|c|c|c|c|c|c|}
\hline Field & & $\begin{array}{r}\text { Squares } \\
\text { Sum }\end{array}$ & $\mathrm{DF}$ & $\begin{array}{l}\text { Squares } \\
\text { Average }\end{array}$ & $\mathrm{F}$ & $\begin{array}{r}\text { Statistical } \\
\text { Significance }\end{array}$ \\
\hline \multirow[t]{3}{*}{$\begin{array}{r}\text { The tool as a } \\
\text { total }\end{array}$} & $\begin{array}{r}\text { Amongst } \\
\text { Groups }\end{array}$ & 0.72 & 3 & 0.24 & \multirow{3}{*}{0.63} & \multirow{3}{*}{0.59} \\
\hline & In Groups & 73.19 & 193 & 0.38 & & \\
\hline & Summation & 73.92 & 196 & & & \\
\hline
\end{tabular}

Table 18 shows that there are no statistically significant differences at the level $(\alpha \leq 0.05)$ of the study-subject opinions, where $(\mathrm{F})$ value is $(0.63)$, which is a non-statistically-significant value. Thus, it can be traced back to the fact that the students share the same academic circumstances.

Recommendations:

1. Arabic-Language-Department lecturers at Jadara University should focus on general linguistic skills, and develop them.

2. Lecturers also should encourage the students to free read in order to enrich their linguistic repertoire.

3. Lecturers should cultivate the students' self-confidence for them to speak in standard Arabic while conversing and debating questions posed by either the lecturers themselves or students.

4. Lecturers should train students to attain critical-thinking skills, considering its importance in both forms of expression: written or oral.

5. Lecturers should train students to acquire deductive skills to infer, generate, and organise ideas.

6. Lecturers should help students to orally express themselves through offering them chances of speaking up in front of audiences.

7. Lecturers should conduct similar studies to examine the expressive-performance level with the study group being of English-Literature, Law, and Media Students.

References:

Ahmed, Jamal (2015). The effect of using self-query strategy in developing some writing and oral skills of nonnative in Arabic sixth-grade students. Reading and Knowledge. (163). P. 121-212.

Al-Badgeh, Abd-Alfattah Hasan. Arabic-Language-and-Literature Skills and their Teaching Methods. Al-Ain: Dar Al-Ketab Al-Jame'e.

Jawwad, Maysoun Ali (2009). The reason why elementary students are weak in oral expression. Education-Faculty Magazine, Al-Mansoura. (2)71. P. 591-607.

Al-Halaq, Ali Sami (2019). The reference in teaching Arabic-Language skills and its sciences. $2^{\text {nd }}$ Print. Beirut: Al-Maseerah: Modern Association Book Company.

Al-Halaq, Ali Sami (2010). Language \& Critical Thinking: Theoretical Principles \& Teaching Strategies. $2^{\text {nd }}$ Print. Amman: Dar-Almaseerah for Publishing, distributing, and printing.

Al-Halaq, Nateq Sa'eed (2013). The Difficulties in teaching Oral-Expression Course for Elementary Stages from the perspectives of both Teachers and Students. Al-Fateh (1)55, P. 97-139.

Al-Khamyseh, Eyad Mohammed Khair (2012).

Al-Khamaiseh, Eyad Mohammed Khair (2012). Arabic-Department Students Level of Oral-Expression Skills at Ha'el University and their in-class struggles from their perspective. The Islamic University for Education and Psychiatry Sciences' Magazine. $20^{\text {th }}$ Tome, $1^{\text {st }}$ Issue. P. 219-242

Al-Rabai'ah, Ibrahim and Al-Habashneh, Quotaybah (2015). The effect of Education-Drama-Employing in Enriching Oral Skills and Academic Results of the non-native speakers of Arabic. Studies, Humanities and Socio-studies. (3) 42, 629-664.

Al-Safasfeh, Abd-Alrahman Ibrahim (2010). Arabic-Teaching Methods. Amman: Al-Falah Library for Publishing and Distribution.

Al-Saffouh, Samir Sayel Ali (2007). Evaluating Oral-Expression Skills of Ninth-Grade Students. Unpublished Master's Thesis. Al-Yarmouk University. Irbid-Jordan

Al-Sayyed, Mahmoud Ahmed (2017). Arabic-Teaching Methods. Part 2. Damascus-University: Education Faculty: the Syrian Arab Republic

Sowman, Ahmed Ibrahim (2014). Arabic Language and its Teaching Methods for the Elementary Stage. Amman: Kunooz Al-Ma'refah House for Publishing and Distribution.

Al-Sweirki, Mohammed Ali (2011). Developing the level of oral-expression skills for the students of the elementary stage in Jordan. Education and Psychiatry Science Magazine. Tome (12), 4th Issue, December 2011. P. 64-86

Abd-Alhameed, Abdullah Abd-Alhameed (1986). Developing the level of oral-expression skills for the students 
of the elementary stage. Unpublished PHD Thesis. Tanta University, Egypt.

Al-Othman, Bassam (1999). The Written-Expression Skills attained by the tenth-grade students in Mafraq Governorate. Unpublished Master's Thesis. Al-Yarmouk University. Irbid, Jordan.

Atta, Ibrahim Mohammed (2006). The 'Reference' in Arabic-Teaching. ${ }^{\text {nd }}$ Edition. Cairo: Al-Ketab Centre for Publishing.

Al-Kalbany, Zuweina Bint Sa'eed bin Rashed (1997). Assessing Oral-Expression Skills of female elementary female. Unpublished Master's Thesis. Al-Sultan Kaboos University.

Madkour, Ali (2007). Arabic-Teaching Methods. Amman: Al-Maseerah for Publishing, Distribution, and Printing.

Naser, Hamdan (1995). Assessing Expressive-Writing Levels for First-Graders in Jordan. Education-Research Centre at Qatar's University. Fourth Year. $4^{\text {th }}$ Edition. P. 192-235 